Proceedings of the 2012 Winter Simulation Conference

C. Laroque, J. Himmelspach, R. Pasupathy, O. Rose, and A.M. Uhrmacher, eds

\title{
CONSTRUCTIVE ALIGNMENT IN SIMULATION EDUCATION
}

\author{
Anders Skoogh \\ Björn Johansson \\ Department of Production Engineering \\ Chalmers University of Technology \\ Göteborg, SE-412 96 SWEDEN
}

\author{
Edward J. Williams \\ Department of Industrial \& Systems Engg. \\ University of Michigan - Dearborn \\ Dearborn, MI 48126 USA
}

\begin{abstract}
Recent and ongoing developments are significantly augmenting both the demand for and the expectations of university simulation education. These developments include increased use of simulation in industry, increased variety of economic segments in which simulation is used, broader variation in demographics of simulation students, and higher expectations of both those students and their eventual employers. To meet the challenges these developments impose, it is vital that simulation educators aggressively and innovatively improve the teaching of simulation. To this end, we explore the application of constructive alignment concepts in simulation education, and compare and contrast its application in the context of two university course offerings. These concepts suggest continuation of some practices and revision of others relative to the learning objectives, learning activities, and assessment tasks in these and other simulation courses.
\end{abstract}

\section{INTRODUCTION}

Demand for and expectations of university simulation education are rising, spurred by several concurrent trends. These trends include increased use of simulation in industry (Carson 2004) and its use in more economic sectors (service, transport (McGuire 1998), health care (Hall et al. 2006), and others (e.g., construction, shipbuilding) in addition to manufacturing. Another trend is increasing variation in student demographics (age, motivation, background, and objectives) - a trend that too often tempts educators into saying "The good students are getting better, and the bad students are getting worse." Yet another trend of significance is increased expectations of students and their prospective employers. Particularly in the United States, students (and their parents!) frequently - as university costs keep rising rapidly - ask "What am I getting for all this [tuition] money?" As the recent recession and ongoing, increasingly severe competitive pressures gnaw at employers, those employers are increasingly likely to demand immediate high productivity, with little or no training or orientation, of their new hires (Preston 2012).

Under the pressure of these rising expectations, university simulation education must continue to improve in its effectiveness. In this paper, we examine the potential for constructive alignment to help in this task, and compare and contrast its potential in two comparable but different university course contexts.

\section{LITERATURE REVIEW}

\subsection{Constructive Alignment}

"Constructive alignment" refers to an academician's "best practice" of (1) defining and formulating good learning objectives, (2) designing interesting, instructive, and motivational learning activities, and (3) selecting good and relevant assessment tasks; and, most importantly, aligning these three things (objectives, 
activities, and assessment tasks) in a strategic way. This concurrence among course design and presentation activities cozily enfold the students in a "web of consistency, optimizing the likelihood that they will engage the appropriate learning activities," as explained in a seminal work (Biggs 1999). Instruction in simulation (indeed, in any field both analytical and creative) works best for newcomers when it provides complete and explicit guidance (Clark, Kirschner, and Sweller 2012).

The definition and formulation of good and strategic learning objectives are the first steps towards changing the traditional focus on what the teacher does to what the students do and actually learn. Learning objectives should consist of active verbs specifying the behaviors and levels of understanding (e.g. knowledge, comprehension, application, analysis, synthesis, and evaluation) that the students should enact and achieve through the course (Biggs 1999). Very good assistance in the selection of such verbs mapping to different levels of understanding is provided in various taxonomies, for example the SOLO taxonomy (Biggs 1982) and Bloom's taxonomy (Bloom 1956). These taxonomies also help the teacher to relate the learning objectives to appropriate grades.

The next step is to select teaching or learning activities motivating and encouraging students to reach the levels of understanding specified in the learning objectives. Higher levels of understanding usually require activities other than the transfer of knowledge obtained in traditional lecturing. Biggs (1999) exemplifies several alternative learning activities categorized as teacher-controlled, peer-controlled, and selfcontrolled. Bonwell and Eison (1991) complements this list with activities classified with regards to the students' activity and risk involved.

Finally, the selection of assessment tasks should also be selected based on the learning objectives. Biggs (1999) suggests several types of assessment methods related to the kind of learning assessed, comparing the levels of understanding described above. The suggestions include tasks classified as extended prose, objective test, performance assessment, and rapid assessments in large classes. The same publication also highlights the advantages of problem-based learning as an effective way of integrating learning activities and assessment tasks while concurrently preparing the students for problems they will meet in their professional careers.

\subsection{Recent Development of Simulation Education}

Simulation education is surely already dynamic, with various significant developments under way. One of these is increased communication, often informal, between simulation practitioners in industry and simulation educators. For example, (Black and Chick 1996) reported concurrence on essential attributes of a high-quality university simulation course - these attributes to include attention to methodology superseding details of using a particular software tool, insistence on a firm foundation of statistical knowledge and awareness, and inclusion of a class project in collaboration with industry (Black and Chick 1996). Standridge et al. (2005) had a panel discussion on how to teach simulation, which came out with a practical approach as the most favorable one since learning by doing is advantageous in the setting of simulation practice. Another valuable innovation in simulation education - indeed, in education in general - is the introduction of games. These games, several of which are described in (Scholz-Reiter et al. 2002), provide realism of stochastic variation, necessary allocation of effort within a team, and immediate, noncritical feedback. Innovatively, (Herper and Ståhl 2003) provide a pair of examples (one German, one Swedish) extending simulation education, with a heavy computer foundation, to the high-school level, using the higher-level language GPSS as opposed to a software modeling tool.

\section{OUTLINE OF THE PAPER}

In the following sections of the paper we present and discuss the course syllabi and student evaluations of two contrasting simulation courses, one taught in Scandinavia and one in the United States. These evaluations, made in the context of the available literature, will identify strengths and weaknesses (hence opportunities for improvement) in these courses, and hence in simulation education in particular. 


\section{SIMULATION EDUCATION AT CHALMERS UNIVERSITY OF TECHNOLOGY}

The course called "Simulation of Production Systems" at Chalmers aims to give the students in-depth skills in DES for simulation of production flows. It is mainly part of the Chalmers Master's Programme in Production Engineering and given the first year after the students have finished their bachelors degree. However, the course is very popular and also frequently taken by students from other master's programmes, for example the education in Systems, Control, and Mechatronics.

A learning centered pedagogy has always been applied in the course. This means that most of the learning takes place in a laboratory environment where the students undertake practical work with the important methodologies and tools in the course syllabus (at present, AutoMod ${ }^{\circledR}$ is used as the DES software package and ExpertFit ${ }^{\circledR}$ for input modeling). All learning activities and assessment tasks are based on open problem solving, meaning that expected outcome of tasks are not specified on a very detailed level. Instead, the deliverables are more specified as objectives allowing several possible solutions, which is common in an industrial context. It becomes important for the students to learn arguing for and against different alternatives.

It should also be mentioned that all courses on a master's level at Chalmers will participate in a constructive alignment project as a part of quality assurance in education. The course in Simulation of Production Systems has not yet participated in the project but this paper is considered to be a first step in this quality-improvement work.

\subsection{Learning Objectives}

The following learning objectives are currently listed in the course syllabus:

- Describe and demonstrate how Discrete Event Simulation can be applied as a tool for increasing sustainability in production.

- Describe and apply essential concepts for Discrete Event Simulation, especially those related to production flows.

- Compare Discrete Event Simulation to other static and/or deterministic production development tools.

- Explain the concept of emulation and list common application areas.

- Describe a systematic methodology for Discrete Event Simulation projects.

- Create a conceptual model describing the logics in production flows.

- Manage the necessary input data for Discrete Event Simulation models.

- Show skills in using a professional Discrete Event Simulation software package.

- Develop stochastic and dynamic models of common manufacturing operations and entire production flows.

- Describe the Theory of Constraints (TOC) and apply it in a simulation context.

- Design a rational experimental plan for increasing efficiency of a modeled production system.

- Apply design of experiments on a simulation model in order to identify improvement options in production systems.

- Argue for and against solutions with the purpose of increasing efficiency in a production system, based on the statistical output from a simulation model.

- Summarize and reflect on a scientific paper and convey the results in an oral presentation with clear illustrations within allotted time.

- Use proper visual aids to support the results of both simulation projects and oral presentations.

- Describe the work procedure and results of a credible simulation project in a well-structured technical report. 


\subsection{Learning Activities}

There is no regular textbook specified in the course syllabus, so most of the learning takes place in scheduled activities and during the students' group assignments and their work in the examination project. In other words, a substantial part of the learning is centered in a laboratory environment and the students motivate and help each other in groups of two. To support the learning during laboratory exercises, students use the Getting Started With AutoMod manual (Banks, 2004) for being introduced to the basics of DES, modeling concepts, steps in a simulation study, and AutoMod ${ }^{\circledR}$ programming.

This "learning by doing" philosophy is of course supported by scheduled activities, such as lectures and presentations of scientific papers. All learning activities are listed below:

Lectures from Chalmers professors are used to convey the fundamentals of DES, common application areas, and steps in simulation studies (see for example Banks et al. 2009). Some of the most important steps, such as input data management and experimental design, are more deeply presented in separate lectures. A separate lecture is also given on the Theory of Constraints (TOC) (Goldratt 1990), which is used as a strategy for iterative improvement of modeled production systems throughout the course. There are also lectures briefly introducing other types of simulation studies in production systems development, e.g. ergonomics and robotics simulations. Finally, the important and developing area of sustainability analyses using DES is presented and promoted by professors from the department of Product and Production Development at Chalmers.

Guest lecturers from industry are very popular among the students. Simulation engineers from industry are invited to share experiences from real-world projects. A consultancy firm also introduces the area of emulation to the students and teaches them to differentiate between emulation and simulation and their different application areas. Guest lecturers from other universities are also popular. For several years, Edward Williams (University of Michigan and PMC) was invited to highlight important aspects of simulation projects; for example, the use of a project notebook. Unfortunately, the course was moved to another quarter, which made it impossible to proceed with this top-ranked (student evaluation) guest lecture.

An introductive tutorial starts already the first day of the course. Its aim is to introduce the students to

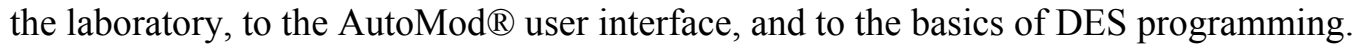

A so called modeling exercise starts right after the first tutorial. The difference between the two learning activities is that the modeling exercise requires the students to build a model from scratch instead of just modifying pre-built models. The aims of the modeling exercise are that the students should learn to model common manufacturing operations, to change the routing of products through the production system, and to create batches using order lists. The modeling exercise also introduces the AutoMod® module called AutoStat ${ }^{\circledR}$ for efficient and simulation-based analysis and development of production systems.

Oral presentations of a scientific paper are also used as a learning activity in the course. Students carefully read a simulation-related paper in groups of two and present the content to the rest of the class. The aim is to provide detailed information on important application areas and crucial steps in simulation studies. Additionally, the presentations hone the students' communication skills. The papers (selected by the teachers) typically describe suggestions for successful simulation projects, verification and validation techniques, data input methodologies, application areas outside the course's manufacturing focus, and relations to other engineering tools (e.g. the digital factory (Kühn 2006)).

Finally, the examination project is probably the most important learning activity, given the learning by practicing philosophy applied in this course. The examination project is further explained in the next section.

\subsection{Assessment Tasks}

Three assessment tasks are used to evaluate the students' performance on all learning objectives. Firstly, the most important assessment task is a comprehensive simulation project including model building and improvements of a fictional but highly realistic production system. Secondly, a written knowledge test is used to cover learning objectives not included in the examination project and to provide an assessment of 
each individual student since the project is performed in groups of two. Finally, the oral presentations of scientific papers are also individually graded. The project results are of chief importance for grading and the other two assessment tasks are mainly used for decision making in borderline cases. This means that students from the same project group can receive different grades if their project result is not clearly in the center of the interval for a specific grade.

As indicated in the section above, the examination project is a good and popular example of integrating learning activities and assessment tasks. The project specification outlines a production system in need of improvements. The specification includes a flow chart of the production equipment and detailed information on each operation with processing times, breakdown patters, scrap rates, et cetera.

The students have 5 weeks ( $70 \%$ of the course) to improve the production system within a given budget. A list of improvement possibilities and the cost for each possible improvement is provided, and the students combine Design of Experiments (DOE) and TOC to reach the highest possible throughput. Options like machine purchases, increased reliability of production equipment, and hiring of new employees are examples of such improvements, but there are also possibilities to increase the throughput for free by changing planning routines, product routing, etcetera. The latter type of improvements often requires better understanding of production systems and DES than just trying various alternatives on the list. Such skills and initiatives are of course awarded in the project grading. The results are reported as a technical report of maximum 20 pages and the entire model code must be attached. The report should cover all aspects of the simulation study that the students want credit for, which usually includes:

- Project methodology and detailed description of important steps.

- Motivations for model assumptions.

- Statistical analysis of breakdown data for some of the work stations.

- The conceptual model.

- Visualization of the simulation model.

- Description of critical or difficult solutions in the model code.

- An experimental plan.

- Arguments for decisions in each improvement iteration (compare TOC).

\subsection{Experiences and Ideas}

Reflections after each class are conducted where two students and involved key teachers meet for an hour to discusses the outcome of a survey which has been filed after the course completion by partaking students. This meeting and the survey provide accurate and relevant support for course development in preparation for next class. During the past ten years the course has matured and the changes from semester to semester are not major anymore. However, an item always present in the discussion is the workload during the main part of the course, the examination project. The majority of students do think that the project work has a heavy workload, but at the same time they report that they learn a lot from the project; see course evaluation examples from 2008 through 2011 in Figure 1 below.

Other experiences from this survey are that there are items not directly related to the project examination which many students then see as unnecessary; however, these extra tasks such as "Oral presentations of a scientific paper" and "Guest lecturers from industry" are present to provide the students with additional influences and experiences for outside the classroom. It can be argued that these extra tasks and hours are worthwhile in terms of experience, but also not that important to achieve a pass on the course.

A reflection which has been made by the authors of this paper is that many students add knowledge achieved from this course in their CVs when applying for work. This is considered positive from a course perspective since the students obviously have achieved sufficient confidence in their own skills and knowledge on simulation to state that they actually can perform work in this area. 

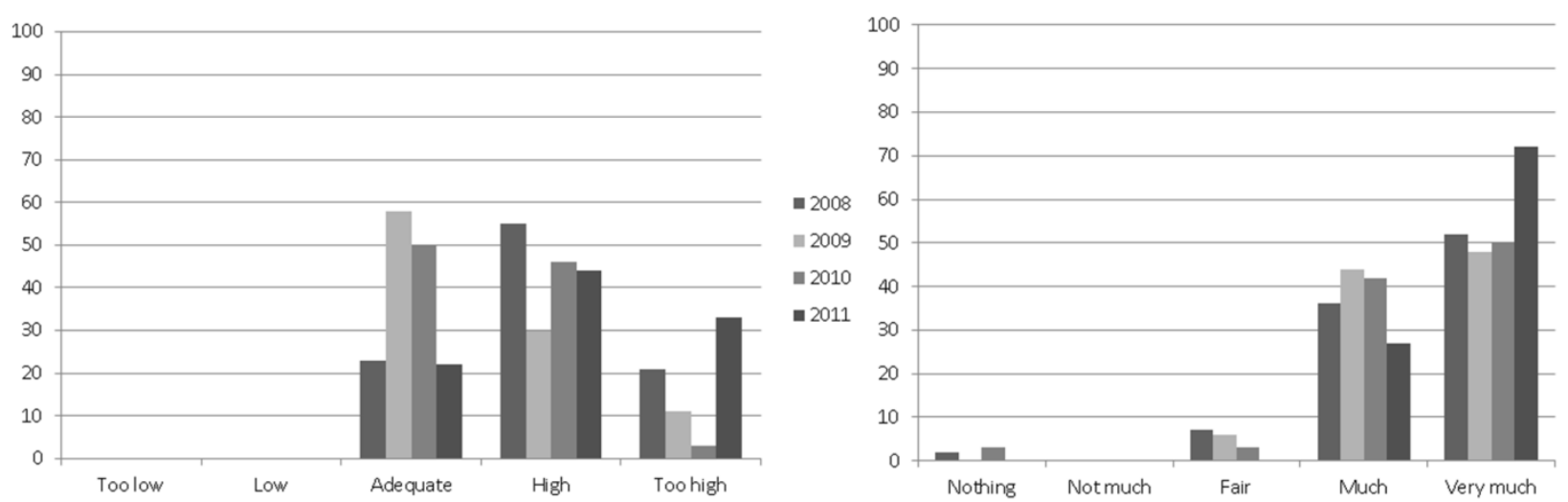

Figure 1. Experienced course workload (left graph) and learning from the project (right graph).

In addition to the discussion above and the surveys, possible identified improvement areas are for example:

- Fewer learning objectives in the course syllabus in order to streamline the learning targets and reach deeper knowledge within the topic. This would also require correspondence and alignment in comparison to the overall program objectives in which the course is one part.

- Update the learning objectives to make sure that they cover the different levels in the SOLO taxonomy in a way which allows students from different backgrounds and ambitions to reach the different grades more clearly. E.g. have an advanced target for higher grades but a more basic target for lower grades. This can be achieved by utilizing the learning objectives and introducing a more detailed learning objective matrix, where activities and objectives can be mapped vs. effort and grades achieved.

- Re-introduce a field trip as a good type of active learning activity (visit a company which is using simulation in order to be introduce students to real cases and a lecture on emulation) (Bonwell and Eison 1991).

To conclude this discussion it should also be mentioned that many of the students taking this course ends up conducting their master thesis project within the same topic; see example in Figure 2. By looking at the track record of previous master thesis projects from 2000 to 2010 we can see that approximately 100 students performed their final thesis project stemming from the topic of simulation from the presented course. Some students stated that this topic is very similar to a computer game, hence a task performed by way of a computer aimed at solving a challenging problem including logical thinking, optimization and visualization. This could be one reason why the course syllabus and execution is motivating students to work hard and learn a lot.

\section{SIMULATION EDUCATION AT UNIVERSITY OF MICHIGAN - DEARBORN}

The undergraduate simulation class at the University of Michigan - Dearborn, offered by the Industrial \& Systems Engineering Department, College of Engineering, is a senior-level one-semester class. Its prerequisites include calculus and one semester of statistics (the statistics prerequisite class also requires calculus). Almost all students taking this class are industrial-engineering majors (the College of Engineering also comprises departments of electrical and computer engineering, mechanical engineering, and computer and information science) who have one or more semesters of programming experience in a language such as $\mathrm{C}$ or $\mathrm{C}++$. 


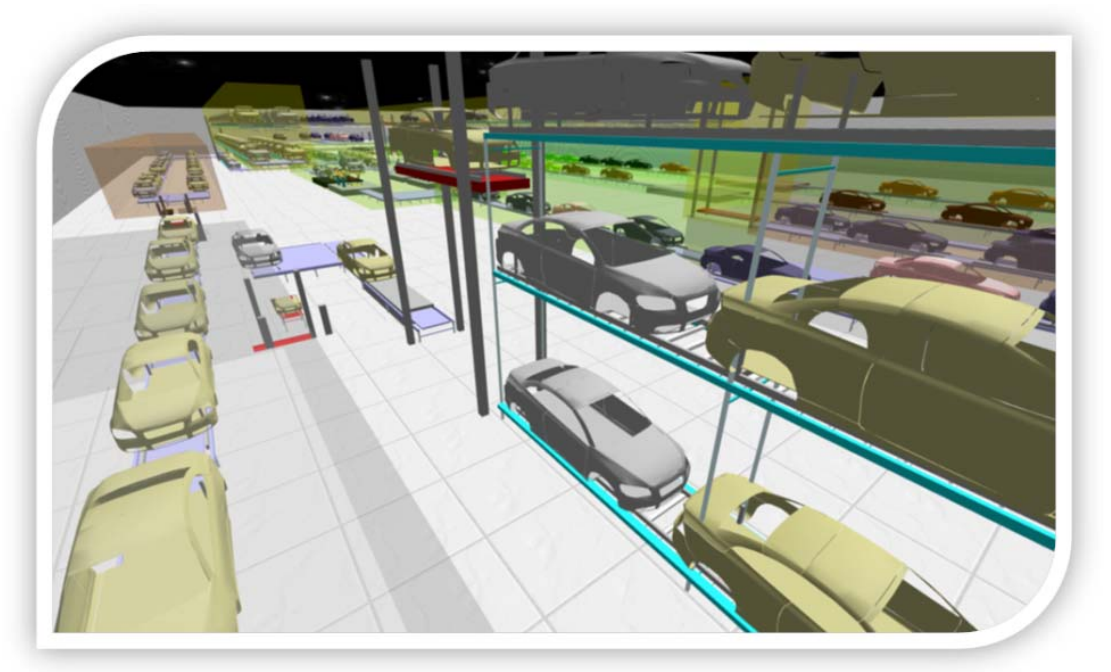

Figure 2: DES model created by students from the Chalmers course.

\subsection{Learning Objectives}

Objectives of this simulation class are, first and foremost, understanding the methods and concepts of discrete-event process simulation, and how it can be used effectively in a variety of situations such as manufacturing, operations management, service industries, delivery of health care, or transportation and supply chain networks. Instruction relies heavily on the students' prior knowledge of statistics to stress the importance of both input data analysis (e.g., distribution fitting and selection, detection of correlations) and output data analysis (hypothesis formulation and testing, choice of steady-state versus terminating analysis, and establishing simulation run length and number of replications). Another significant learning objective is that of interrelating the simulation course to other courses in the industrial-engineering curriculum, particularly the operations management, work measurement, and supply-chain analysis courses. Thus these objectives are highly similar with those at Chalmers (section 4.1 above).

\subsection{Learning Activities}

In accordance with the learning objectives, the class uses two textbooks: The (Banks et al. 2009) overview of simulation and a textbook describing one simulation software package in detail. In various years, with fluctuations due largely to expressed desires of large local employers, the simulation software package of choice has been SIMUL8 ${ }^{\circledR}$, ProModel ${ }^{\circledR}$, and, most recently, Arena ${ }^{\circledR}$ (Kelton, Sadowski, and Swets 2010). Use of Simio ${ }^{\circledR}$ is under serious consideration. Learning activities include the class lectures and a weekly laboratory (three lecture hours and three laboratory hours per calendar week). Throughout the course, students are strongly urged to work in self-selected teams. Since this course is senior-level, the students taking it each year typically know one another from previous courses, and can hence readily and comfortably select teammates based on knowledge of classmates' particular interests, work habits, and schedules. Students on a team receive identical grades unless they present a document, signed by all team members, to the instructor supporting different allocation of credit. Such documents are usually occasioned by transient illness or heavy job responsibilities of one team member resulting in reduced team participation. The University of Michigan - Dearborn, unlike its larger parent campus at Ann Arbor, is a "commuter campus." That is, a heavy majority of students, even undergraduates, work (often about 20 hours per week) as well as attend university. Early in the course, the homework and laboratory assignments ask the students to undertake small input and output analyses, and to build small simulation models. Later in the course, the students are required, in their teams, to seek out a commercial simulation application; build, verify, and validate a model pertinent thereto; and present their findings both to the client and to their classmates. These projects typically have venue where one member of a team, and/or his or 
her relatives or close friends, is employed. Examples of these projects have included a simulation to improve efficiency of scheduling and staffing at a dental clinic (Czech, Witkowski, and Williams 2007) and a model analyzing a transmission plant assembly line (Dunbar, Liu, and Williams 2009). Hence these learning activities are also similar to those at Chalmers (section 4.2 above).

\subsection{Assessment Tasks}

Assessment of student achievement in this class is based upon:

- Performance on a mid-semester examination and on a final examination.

- The quality and timeliness of the semester project, determined partly as assessed by the client.

- Class participation throughout the semester.

- Quality and timeliness of solutions submitted to the smaller homework problems assigned during the first half of the semester.

- Students' peer ratings of one another's team performances.

Of these criteria, the first two carry significantly greater weights.

\subsection{Experiences and Ideas}

Students who have taken this class report (for example, in questionnaires sent to recent graduates) that the semester simulation project for an external client is of significant value, partly as a learning experience partly as an introduction to the realities of applying "textbook" concepts in the workplace, and partly as an opportunity to see interrelationships among simulation work, ergonomic concerns, supply chain issues, and statistical quality control. For some students, the professional alliances made during this project have smoothed their entry into the workforce, and for those few students whose projects merited conference publication in application papers, the course significantly supported admission to graduate school - sometimes in a business curriculum, e.g., to earn the Master of Business Administration [MBA] degree, a credential which takes on added luster in the United States workforce when supported by an undergraduate degree in engineering. Many alumni have also reported that the high emphasis placed on teamwork in this class is useful preparation for the role of industrial engineers in the workplace.

\section{DISCUSSION AND COMPARISON OF THE COURSES}

The typical student in the Chalmers University of Technology course is in his or her early-to-mid twenties, and has recently obtained an undergraduate degree in industrial and/or process engineering. These students are enrolled in several technical master's degree programs, adding to the possibilities of productive student-to-student exchanges of perspectives during the course. Most of these students have not yet undertaken full-time professional work, although many have undertaken summer internships, sometimes abroad. The course lasts one semester or about eight calendar weeks.

The typical student in the University of Michigan - Dearborn course is a senior (i.e., last academic year before receipt of the undergraduate degree) and almost surely majoring in industrial and systems engineering. Most students are in their early twenties. Graduate-level students are normally not allowed to enroll in this course; a separate master's-level course with more theoretical overtones is available to them. As at Chalmers University of Technology, a majority of students have not worked full-time at professional positions, although some have undertaken internships (very rarely abroad). However, a significant minority of the students are older, have worked full-time outside of the university environment, and are now returning to university to complete undergraduate education. Many of these students spent the first two years of the nominally four-year undergraduate course at a "community college" - a peculiarly American institution whose role is often to provide the first half of an undergraduate program at prices much more affordable to students from middle-class families.

It might also be of interest to compare these two courses to other university educations having reached even further in their implementation of constructive alignment concepts. Every year, Chalmers arranges an internal conference to exchange experiences between courses having participated in the con- 
structive alignment project mentioned in section 4. One common discussion during these gatherings is whether constructive alignment really improves education quality or if the concept (and its "stiff" structure) limits the creativity of professional and motivated teaching staff. However, most course examiners find that they can use the ideas of constructive alignment in creative way and adapt various learning activities and assessment tasks to the objectives of their specific courses. Another positive aspect is that clearer explanation of objectives, activities, and tasks facilitates the communication to other courses and to the students. This makes it easier to share experiences, to align the content between different courses within the same education program, and to give students proper expectations before starting the course.

\section{CONCLUSIONS}

This paper describes how the pedagogical concept called constructive alignment can be applied in simulation education. Two comparable courses, one from Chalmers University of Technology, Sweden, and one from University of Michigan at Dearborn, USA, are compared and contrasted in order to describe their current use and future potential in aligning three fundamental components: learning objectives, learning activities, and assessment tasks. A common result is that both courses report great potential for simulation education to align these three components thanks to the interactive nature of production systems development using simulation. Also, both courses, with their statistical prerequisites and repeated instructional emphasis on use of statistical methods, successfully remedy the situation decried in (Eschenbacher 1995): that "[M]any new simulationists are not able to interpret their results correctly because they lack of [sic] statistical...knowledge." These interactions, and the close connection between gaming and simulation, provide very good opportunities for designing highly motivating learning activities and further to integrate them in a smart way with the assessment tasks. Constructive alignment also helps the students to achieve a unified conceptual flow along the path recommended by (Garcia and Centeno 2009): design the model, build the model, and experiment with the model. Furthermore, this aligned path draws attention to the reality that discrete-event simulation problems, in sharp contrast to the calculus and statistics problems all the students have seen, do not have one correct answer obtainable by using the formulas appearing in the textbook chapter of the problem. Having come to terms with this reality, students can be trusted not to oversimplify a system analysis by focusing on only one component of the system. Despite the potential of applying constructive alignment and simulation education, it is difficult to find documented implementations of the concept to enhance simulation courses. The authors strongly believe that constructive alignment can help strengthening simulation education world-wide and recommend other lecturers within the field to study available materials in the area (see the reference list for some good examples).

\section{ACKNOWLEDGMENTS}

Parts of this work has been performed within the Sustainable Production Initiative and the Production Area of Advance at Chalmers. The support is gratefully acknowledged.

The authors gratefully acknowledge their respective department chairpersons and faculty mentors, who have guided their professional development, not only as industrial engineers, but also as educators.

\section{REFERENCES}

Banks, J., Carson II J. S., Nelson, B. L., and D. M. Nicol. 2009. Discrete-Event System Simulation, $5^{\text {th }}$ edition. Upper Saddle River, New Jersey: Pearson Education, Incorporated.

Banks, J. 2004. Getting Started with AutoMod (2 ${ }^{\text {nd }}$ ed.). AutoMod user manual. ISBN 0-9729100-3-4.

Biggs, J. B. and R. E. Collis. 1982. Evaluating the quality of learning: The SOLO taxonomy. New York: Academic Press

Biggs, J. 1999. What the Student Does: Teaching for Enhanced Learning. In Journal of Higher Education Research \& Development (18:1), 57-75. 
Black, J. J. and S. E. Chick. 1996. Michigan Simulation User Group Panel Discussion: How Do We Educate Future Discrete Event Simulationists? In International Journal of Industrial Engineering: Applications and Practice (3:4), 223-232.

Bloom, B. S. 1956. Taxonomy of educational objectives. Handbook I: Cognitive domain. New York: David McKay.

Bonwell, C. C. and J. A. Eison. 1991. Active Learning: Creating Excitement in the Classroom, ASHEERIC Higher Education Report No. 1. Washington, D.C.: The George Washington University, School of Education and Human Development.

Carson, J. S. II. 2004. Introduction to Modeling and Simulation. In Proceedings of the 2004 Winter Simulation Conference, Volume 1, edited by Ricki G. Ingalls, Manuel D. Rossetti, Jeffrey S. Smith, and Brett A. Peters, 9-16.

Clark, R. E., Kirschner P. A., and J. Sweller. 2012. Putting Students on the Path to Learning: The Case for Fully Guided Instruction. American Educator (36:1)6-11.

Czech, M., Witkowski M., and E. J. Williams. 2007. Simulation Improves Patient Flow and Productivity at a Dental Clinic. In Proceedings of the $21^{\text {st }}$ European Conference on Modelling and Simulation, edited by Ivan Zelinka, Zuzana Oplatkov, and Alessandra Orsoni, 25-29.

Eschenbacher, P. 1995. Handbook on Simulation. In Proceedings of the $7^{\text {th }}$ European Simulation Symposium, edited by Mario Dal Cin, Ulrich Herzog, Gunter Bolch and Alı Riza Kaylan, 788-792.

Garcia, H., and M. A. Centeno. 2009. S.U.C.C.E.S.S.F.U.L.: A Framework for Designing Discrete Event Simulation Courses. In Proceedings of the 2009 Winter Simulation Conference, edited by Manuel D. Rossetti, R.R. Hill, B. Johansson, A. Dunkin and R. G. Ingalls, 289-298. Piscataway, New Jersey: Institute of Electrical and Electronics Engineers, Inc.

Goldratt, E. M. 1990. What is This Thing Called Theory of Constraints and How Should it be Implemented? New York: North River Press.

Dunbar III J. F., Liu J-W., and E. J. Williams. 2009. Simulation of Alternatives for Transmission Plant Assembly Line. In Proceedings of the 2009 Summer Computer Simulation Conference, edited by Osman Balci, Maarten Sierhuis, Xiaolin Hu, and Levent Yilmaz, 17-23.

Hall, R., Belson D., Murali P. and M. Dessouky. 2006. Modeling Patient Flows Through the Healthcare System. In Patient Flow: Reducing Delay in Healthcare Delivery, edited by. Randolph W. Hall. Los Angeles, California: Springer-Verlag, 1-44.

Herper, H., and I. Ståhl. 2003. Modeling and Simulation in High School Education - Two European Examples. In Proceedings of the 2003 Winter Simulation Conference, Volume 2, edited by Stephen E. Chick, Paul J. Sánchez, David Ferrin, and Douglas J. Morrice, 1973-1981. Piscataway, New Jersey: Institute of Electrical and Electronics Engineers, Inc.

Kelton, W. D., Sadowski R. P., and N. B. Swets. 2010. Simulation with Arena, $5^{\text {th }}$ edition. Boston, Massachusetts: The McGraw-Hill Companies, Incorporated.

Kühn, W. 2006. Digital Factory - Simulation Enhancing the Product and Production Engineering Process. In Proceedings of the 2006 Winter Simulation Conference, edited by L.F. Perrone, F.P. Wieland, J. Liu, B.G.Lawson, D.M. Nicol, and R.M. Fujimoto, 1899-1906. Piscataway, New Jersey: Institute of Electrical and Electronics Engineers, Inc.

McGuire, F. 1998. Simulation of Logistics and Transportation Systems. In Handbook of Simulation: Principles, Methodology, Advances, Applications, and Practice, edited by Jerry Banks. New York, New York: John Wiley \& Sons, Incorporated, 571-604.

Preston, R. 2012. Skills Shortage? So What Are You Doing About It? Information Week (Issue 1327):44 (12 March 2012)

Scholz-Reiter, B., Echelmeyer, W., Hamann T., and J. Hoheisel. 2002. Games for Engineering Education. In Proceedings of the $16^{\text {th }}$ European Simulation Multiconference, edited by Krzysztof Amborski and Hermann Meuth, 391-394.

Standridge, C.R., Centeno, M., Johansson, B., and I. Stahl. 2005. Introducing Simulation Across the Disciplines, In Proceedings of the 2005 Winter Simulation Conference, edited by. Kuhl, M.E., Steiger, 
N.M., Armstrong, F.B., Joines, J.A., Orlando, Florida, 4-7 Dec. Piscataway, New Jersey: Institute of Electrical and Electronics Engineers, Inc.

\section{AUTHOR BIOGRAPHIES}

ANDERS SKOOGH is a researcher and lecturer in the area of Virtual Production Systems at the Department of Product and Production Development, Chalmers University of Technology, Sweden. He received his master's degree in automation and mechatronics engineering in 2005, the degree of Licentiate of Engineering in 2009, and his PhD in Production Systems in 2011, all from Chalmers. Before starting his research career, he accumulated industrial experience from an employment as a logistics developer at Volvo Car Corporation. His main research area is virtual tools for decision support in development of sustainable production systems. The current focus is on efficient input data management in simulation of production flows, for example by developing and evaluating methodologies for automated data processing. His email address is anders.skoogh@chalmers.se.

BJÖRN JOHANSSON is Associate Professor and vice head of Production Systems division at the Department of Product and Production Development, Chalmers University of Technology, Sweden. He serves as Production Modeling Corporation director for the European office in Gothenburg. His research interest is in the area of discrete-event simulation applied for manufacturing industries, including environmental effects modeling, modular modeling methodologies, software development, user interfaces, and input data architectures. His email address is bjorn.johansson@chalmers.se.

EDWARD WILLIAMS holds bachelor's and master's degrees in mathematics (Michigan State University, 1967; University of Wisconsin, 1968). From 1969 to 1971, he did statistical programming and analysis of biomedical data at Walter Reed Army Hospital, Washington, D.C. He joined Ford Motor Company in 1972, where he worked until retirement in December 2001 as a computer software analyst supporting statistical and simulation software. After retirement from Ford, he joined PMC, Dearborn, Michigan, as a senior simulation analyst. Also, since 1980, he has taught classes at the University of Michigan, including both undergraduate and graduate simulation classes using GPSS $/ \mathrm{H}^{\mathrm{TM}}$, SLAM II ${ }^{\mathrm{TM}}$, SIMAN ${ }^{\mathrm{TM}}$, ProModel ${ }^{\circ}$, SIMUL8 ${ }^{\circledR}$, or Arena ${ }^{\circledR}$. He is a member of the Institute of Industrial Engineers [IIE], the Society for Computer Simulation International [SCS], and the Michigan Simulation Users Group [MSUG]. He serves on the editorial board of the International Journal of Industrial Engineering - Applications and Practice. During the last several years, he has given invited plenary addresses on simulation and statistics at conferences in Monterrey, México; İstanbul, Turkey; Genova, Italy; Rīga, Latvia; and Jyväskylä, Finland. He served as a co-editor of Proceedings of the International Workshop on Harbour, Maritime and Multimodal Logistics Modelling \& Simulation 2003, a conference held in Rīga, Latvia. Likewise, he served the Summer Computer Simulation Conferences of 2004, 2005, and 2006 as Proceedings co-editor. He is the Simulation Applications track co-ordinator for the 2011 Winter Simulation Conference. His email address iswilliame@umd.umich.edu. 